\title{
Falando sobre experiência estética para pensar o lugar da mediação
}

\section{Talking about aesthetic experience to think about the place of mediation}

\section{Arlene von Sohsten}

Arlene von Sohsten

Mestra em Artes Cênicas pela Universidade de Brasília (UnB)

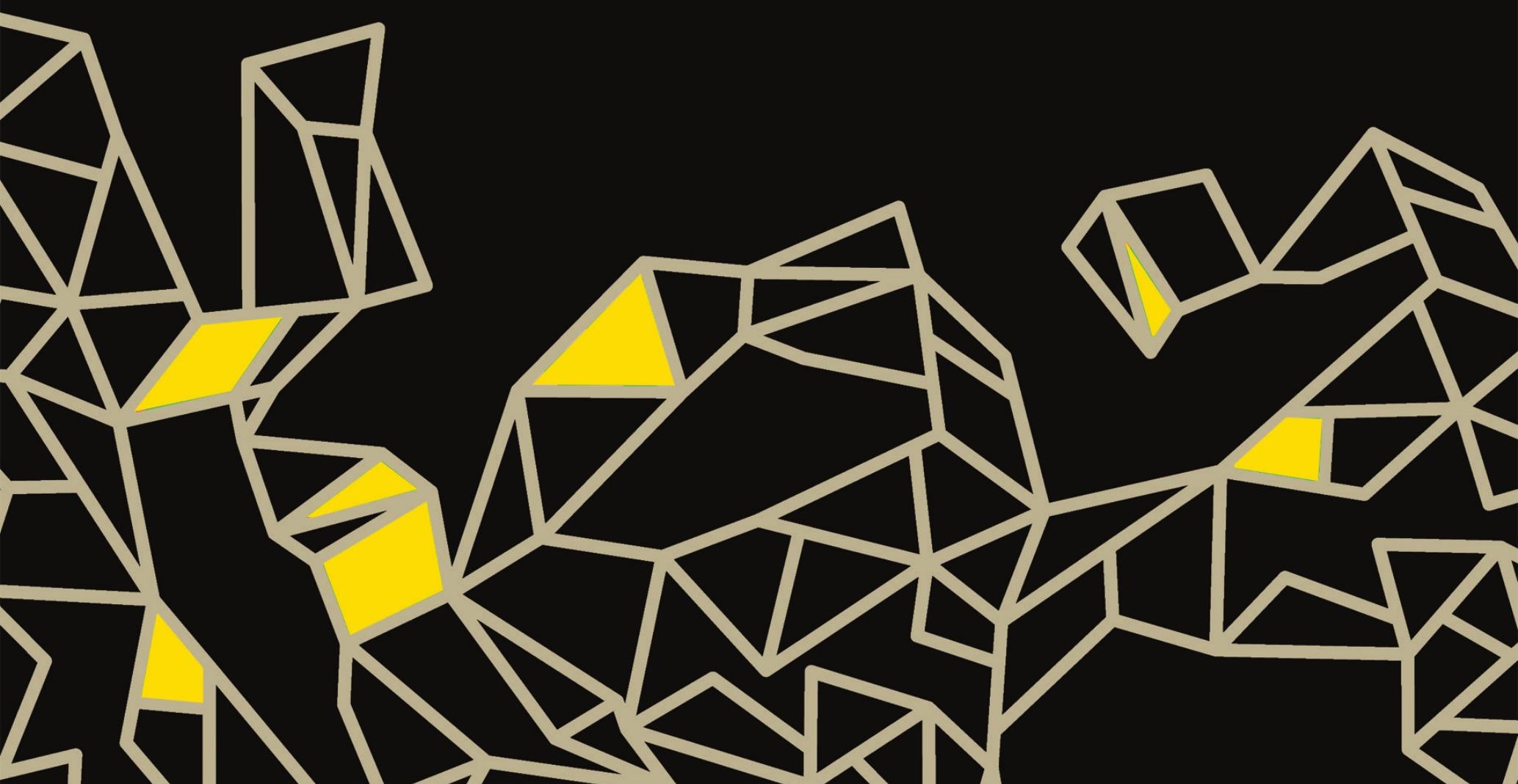




\section{Resumo}

Pretende-se, neste artigo, desfiar um entendimento para o que se chama experiência estética na arte a partir de semelhanças encontradas entre a personagem G.H., de Clarice Lispector, e os escritos de Georges Didi-Huberman sobre a relação entre olhante-olhado; bem como explicitar a posição do sujeito na experiência. Por fim, esse lugar encontrado para o sujeito da experiência será também o lugar da mediação.

Palavras-chave: Experiência estética, Olhar, Mediação.

\section{Abstract}

This article is intended to unravel an understanding about what is known as aesthetic experience in art from similarities found between Clarice Lispector's character G.H. and the writings of Georges Didi-Huberman on the relationship between observer and observed, as well as to explore the subject's position in the aesthetic experience. Finally, such subject's position is also the place where the mediation occurs.

Keywords: Aesthetic experience, Observation, Mediation.

Jorge Larrosa Bondía (2002, p. 25) tece alguns princípios sobre experiência que não se restringem ao âmbito artístico, mas serão aqui voltados para a relação estética com a arte. Primeiro, o sujeito da experiência como um território de passagem e como um espaço onde têm lugar os acontecimentos; segundo, o sujeito da experiência como um sujeito "ex-posto", pois "é incapaz de experiência aquele que se põe, ou se opõe, ou se impõe, ou se propõe, mas não se 'ex-põe"'; terceiro, a experiência como travessia e perigo; e quarto, a experiência como paixão. Sobre esta última, Bondía (Ibid., p. 26) esclarece:

Se a experiência é o que nos acontece, e se o sujeito da experiência é um território de passagem, então a experiência é uma paixão. Não se pode captar a experiência a partir de uma lógica da ação, a partir de uma reflexão do sujeito sobre si mesmo enquanto sujeito agente, a partir de uma teoria das condições de possibilidade da ação, mas a partir de uma lógica da paixão, uma reflexão do sujeito sobre si mesmo enquanto sujeito passional. 
O autor, ao colocar o sujeito passional, não está pressupondo a mera passividade, mas um sujeito paciente, que assume o padecimento, que suporta, que aceita e, até mesmo, que tem sua própria força produtiva. E quanto à paixão, propriamente dita, refere-se a sua relação intrínseca com a morte, mas uma morte desejada como verdadeira vida, como renascimento. Refere-se, ainda, ao sujeito apaixonado não como detentor do objeto amado, mas sim possuído por ele.

Veremos que a paixão será compreendida de forma semelhante em $A$ paixão segundo G.H. de Clarice Lispector - mesmo que não se fale explicitamente dela. As quatro dimensões da experiência colocadas por Bondía (Ibid.) estão presentes na narrativa de G.H. - sujeito exposto e tido como território de passagem; experiência como travessia, perigo e paixão. Tais dimensões, cabe antecipar, estão presentes também na experiência estética e nos processos de mediação.

O livro de Lispector é uma espécie de exercício da linguagem como possibilidade de tocar o intocável, falar o inefável, no qual a autora se apropria da escrita em forma de fluxo de pensamento. A personagem G.H. (narradora no livro) passa por uma experiência de autoconhecimento dentro de um cômodo de sua própria casa. O trajeto feito para o interior desse lugar - o quarto de empregada, no qual ela não entrava há muito tempo - pode facilmente servir de metáfora para a entrada em si própria, como uma entrada no desconhecido. G.H. explicita isso: "o quarto desconhecido. Minha entrada nele se fizera enfim. [...] como se eu fosse também o outro lado do cubo, o lado que não se vê porque se está vendo de frente [...]. E na minha grande dilatação, eu estava no deserto." (LISPECTOR, 1995, p. 63-64).

Ao entrar no quarto, G.H. é primeiramente surpreendida com a imensa claridade vinda da janela e com o vazio do cômodo: não havia nada além de um guarda-roupa e uma cama com colchão. A personagem faz inclusive uma analogia do quarto com o deserto. Este cenário, presente em algumas passagens da narrativa cristã, pode ser interpretado como local de um processo de autoconhecimento pela via de uma experiência de provação, na qual as noções de travessia, sujeito exposto e perigo estão claramente presentes.

Outra surpresa para a personagem foi o desenho, feito em carvão, de três silhuetas na parede branca (um homem, uma mulher e um cachorro), 
deixado por Janair (a empregada). Por fim, a personagem se depara com uma barata na porta do guarda-roupa. A partir de então se desenvolve todo um processo de epifania. Ela passa por uma experiência na qual se conhecer é perder-se, ou seja, o que proporciona o autoconhecimento carrega também a perspectiva da perda - processo explicitado pela fala de Didi-Huberman, que será explorada adiante -, e busca então a própria identidade. A silhueta nua e inquietante desenhada na parede, num dado momento de reflexão, torna-se a pura representação do seu vazio interior. O vazio da silhueta revela, como reflexo, o seu insuportável vazio.

Segundo a personagem, a entrada para o quarto só tinha uma passagem, estreita: passando pela barata. Se encararmos a barata como metáfora da resistência, da permanência e da imutabilidade, por sua própria forma de vida na Terra, e também como objeto do medo e do ódio da personagem, poderemos dizer que G.H. fez a travessia superando a sua própria permanência pacífica, rumo ao desconhecido, ao temido, ao revelador. E nessa travessia há inevitavelmente o perigo e a exposição.

Pressionada por G.H., a porta do guarda-roupa esmaga o inseto no meio, partindo-o em dois. Antes, a personagem via apenas a exterioridade da coisa, mas a partir dessa cisão ela vê a vida, a essência da coisa: a massa branca da barata. G.H. dá-se a uma dupla visão: do fora e do dentro. A personagem passa então a experienciar o conhecimento de si mesma através do outro (a barata). O que é a experiência estética com a arte senão um encontro com a obra e consigo mesmo?

A cisão da barata seria então a metáfora de um processo de alteridade. E se tomarmos Didi-Huberman (2010, p. 29), seria a cisão, também, um paradoxo da visão:

O que vemos só vale - só vive - em nossos olhos pelo que nos olha. Inelutavelmente porém é a cisão que separa dentro de nós o que vemos daquilo que nos olha. Seria preciso assim partir de novo desse paradoxo em que o ato de ver só se manifesta ao abrir-se em dois. Inelutável paradoxo.

Além da cisão, a perspectiva da perda também pode ser encontrada em Lispector e em Didi-Huberman. Suas respectivas escritas se desdobram 
de forma semelhante quando desfiam suas imagens ambivalentes. DidiHuberman trata da experiência estética pela via do que está entre o que vemos e o que nos olha. Para ele, ver é perder quando algo nos olha como uma obra visual de perda, e a ausência nos ameaça.

nossa desorientação do olhar implica ao mesmo tempo ser dilacerados pelo outro e ser dilacerados por nós mesmos, dentro de nós mesmos. Em todo caso perdemos algo aí, em todo caso somos ameaçados pela ausência. Ora, paradoxalmente, essa cisão aberta em nós - cisão aberta no que vemos pelo que nos olha - começa a se manifestar quando a desorientação nasce de um limite que se apaga ou vacila. (Ibid., p. 231, grifo do autor)

Lispector (1995, p. 15-16) explicita esse processo em G.H.:

Perdi alguma coisa que me era essencial, e que já não me é mais. Não me é necessária, assim como se eu tivesse perdido uma terceira perna que até então me impossibilitava de andar mas que fazia de mim um tripé estável.

Além da perda, há, por consequência, uma desorientação. G.H. tenta verbalizar a experiência, mas há uma completa perturbação do olhar. Vai compreendendo de forma fragmentária, à medida que vai narrando. Tem medo do que viveu e da instabilidade, da vulnerabilidade que isso Ihe causa. Tem medo da perda e do vazio, uma vez que o vazio a desorienta. Ela não compreende o que viu, nem mesmo sabe se viu, já que seus olhos acabaram não se diferenciando da coisa vista. "Eu sou a barata", diz G.H. (Ibid., p. 69).

Ora, não é exatamente dessa matéria que trata a experiência estética com a arte? O olhante e o olhado se fundem em determinado momento. Da mesma forma que a personagem se funde com a coisa vista, sem mais saber delimitar o que é ela mesma e o que é o outro, assim também o espectador se funde à obra em experiência. "O mundo só não me amedrontaria se eu passasse a ser o mundo" (Ibid., p. 95). G.H. passa a ser a coisa, mas diferentemente do que acontece no processo kafkiano de $A$ metamorfose, ela possui a coisa em carne: come a barata, sua massa branca, sua essência. No entanto, é importante observar que esse processo de fusão não exclui a individuação (posterior): há um ir e vir. G.H. não permanece perdida na epifania, ela retorna 
a si (transformada), conta o que lhe aconteceu e à medida que narra o que viveu vai tomando consciência da sua experiência.

O que Lispector escreveu sobre a experiência epifânica da personagem com a barata bem poderia ter sido escrito sobre a relação do espectador com a obra de arte. Há um processo que a isso se assemelha: G.H entra no quarto; assim como a personagem, o espectador entra no espaço da experiência. Ela encara a barata (o outro, desconhecido); e ele (espectador) trava um duelo de sentidos com a arte. A personagem intenta contra a vida do inseto, partindo-o ao meio; assim também o espectador provoca uma cisão no que vê, na medida em que considera não apenas o que vê, mas também o que o olha, ou seja, abre-se para a experiência. G.H. vê a massa branca exposta da barata, se funde àquela essência, que é a matéria pura da vida, e a come; o espectador em experiência estética ultrapassa a superficialidade, se funde à obra, às vezes sem saber diferenciar o que é ele mesmo e o que é arte, estabelecendo assim uma comunhão. G.H. retorna ao seu cotidiano, não mais a mesma, transformada; o espectador retorna a si mantendo o processo de individuação. Ambos, G.H. e o espectador, se expõem e permitem que algo lhes aconteça, se permitem a vulnerabilidade; ambos passam por um processo de reconhecimento de si mesmos no outro, de alteridade e de retorno; ambos assumem a travessia e o perigo.

Didi-Huberman (2010) traz em seu livro O que vemos, o que nos olha um personagem chamado Stephen Dedalus, protagonista e anti-herói de romances de James Joyce - também considerado alter ego literário do autor. Ao fazer alusão a esse personagem, Didi-Huberman evoca o que nos olha, na medida em que tudo o que ao personagem se apresenta é olhado a partir da perda de sua mãe. Qualquer coisa que é por ele olhada, por mais neutra que pareça ser, será vista pela perspectiva da perda - como se fechar definitivamente as pálpebras de sua mãe permitisse que agora ela o olhasse.

Mas a conclusão da passagem joyciana - "fechemos os olhos para ver" - pode igualmente, e sem ser traída, penso, ser revirada como uma luva a fim de dar forma ao trabalho visual que deveria ser o nosso quando pousamos os olhos sobre o mar, sobre alguém que morre ou sobre uma obra de arte. Abramos os olhos para experimentar o que não vemos, o que não mais veremos - ou melhor, para experimentar que o que não vemos com toda a evidência (a evidência visível) não obstante nos olha como uma obra (uma obra visual) de perda. (Ibid., p. 34, grifos do autor) 
Assim como a mãe do personagem não cessa de olhá-lo, algo também nos olha quando fitamos algo. Da mesma forma que Stephen Dedalus não via unicamente o mar ao olhá-lo, mas algo além - e esse além era a morte (a que foi e a que está por vir) -, assim também podemos ver além ao entrarmos em contato com a arte. O que leva o personagem a ver fora da evidência dada ao olhar são os olhos fechados de sua mãe; por isso a ambiguidade em "fechemos os olhos para ver.' E abrir os olhos para experimentar o que não vemos é permitir a abertura necessária para que aquilo que olhamos também nos olhe, ou seja, é a cisão, quando o olhar se parte em dois.

Ao final da citação de Didi-Huberman, o autor fala justamente da necessidade de um olhar para a arte que se assemelhe a esse olhar de morte e de perda (acrescentar-se-ia, ainda, de paixão). Não há nada de confortável na perda. A inquietude é, portanto, o estado desejado para o olhar. DidiHuberman (Ibid., p. 34) afirma que em geral temos a impressão de ganhar algo na experiência de ver, mas essa sensação de ter é enganosa, uma vez que "a modalidade do visível torna-se inelutável - ou seja, votada a uma questão de ser - quando ver é sentir que algo inelutavelmente nos escapa, isto é: quando ver é perder." Essa perda está diretamente relacionada com a inquietude e a desorientação na experiência de ver; presente também em G.H. quando esta remonta à perda de uma terceira perna, que a tira da configuração de tripé e a desestabiliza. Mas, ao mesmo tempo, é essa perda inquietante que gera a vida.

Bondía (2002, p. 26) também explicita essa relação entre vida e morte, apontando-a inclusive como característica mesma da paixão - tal qual a paixão segundo G.H.:

A paixão tem uma relação intrínseca com a morte, ela se desenvolve no horizonte da morte, mas de uma morte que é querida e desejada como verdadeira vida, como a única coisa que vale a pena viver, e às vezes como condição de possibilidade de todo renascimento.

A perspectiva do objeto que olha o sujeito, em Didi-Huberman, é explicitada por meio da imagem ambivalente do túmulo. Ambivalente porque o túmulo é colocado pelo autor como objeto que recolhe um corpo morto, o que gera dor; e também como objeto esvaziado pela fé, por exemplo, na tradição cristã, o que gera uma certeza alegre. 
Nesse segundo caso, a pessoa - por meio da fé, que é a convicção em fatos que não se veem, ou a certeza em algo que está por vir - está certa de que o túmulo é um invólucro que guarda apenas outro invólucro, também material, ou seja, um corpo que um dia foi receptáculo de um espírito que não está mais ali. Um segundo tipo de esvaziamento, mais literal (se é que isso pode ser dito) e não mais referente a uma pessoa qualquer, diz respeito à mística máxima do cristianismo. A despeito de alguns teóricos que postulam o roubo do corpo de Jesus Cristo, a tradição cristã crê na ressurreição, ou seja, que o espírito e o corpo já não se encontram mais no seu túmulo, porque Cristo ressuscitou. Dessa forma, pelos olhos da fé, assim como o túmulo de Jesus foi esvaziado, inclusive de seu corpo físico, também os túmulos de entes queridos são esvaziados pelos cristãos.

Em outras palavras, o túmulo carrega duas forças, em sentidos conflitantes, ou ao menos diferentes, como podemos ver nas palavras de Didi-Huberman:

Por um lado, há aquilo que vejo do túmulo, ou seja, a evidência de um volume, em geral uma massa de pedra mais ou menos geométrica, mais ou menos figurativa, mais ou menos coberta de inscrições: uma massa de pedra trabalhada seja como for [...]. Por outro lado, há aquilo, direi novamente, que me olha: e o que me olha em tal situação não tem mais nada de evidente, uma vez que se trata ao contrário de uma espécie de esvaziamento. (DIDI-HUBERMAN, 2010, p. 37, grifos do autor)

Ao trazer a metáfora do túmulo (ou fábula, como o próprio autor a chama), Didi-Huberman (Ibid.) apela, em última instância, para um objeto que, inevitavelmente, lança um olhar sobre o sujeito observador - inclusive na questão da fé. O túmulo é o objeto que tira a capacidade do sujeito de olhá-lo como simples volume geométrico, de cimento, de madeira, de mármore. Objeto que mostra ao sujeito que ele perdeu o corpo recolhido em seu interior.

Em G.H. também está presente o olhar do olhado para o olhante:

A barata com a matéria branca me olhava. [...] Mas seus olhos não me viam, a existência dela me existia. [...] [o] que nela é exposto é o que em mim eu escondo: de meu lado a ser exposto fiz o meu avesso ignorado. 
Ela me olhava. [...] Os dois olhos eram vivos como dois ovários. Ela fertilizava a minha fertilidade morta. (LISPECTOR, 1995, p. 80-81)

A imagem dada ao final da citação por Lispector - de fertilizar e dar vida - traz a ideia da paixão como o renascimento, presente em Bondía (2002), e traz também toda a potência da criação do espectador em experiência com a obra. A obra fertiliza o espectador, e este permite que a obra aconteça. Essa imagem cíclica explicita uma relação de mútua alimentação e envolvimento.

Em contraponto à cisão necessária ao olhar, Didi-Huberman (2010) fala do evitamento do vazio. Trata-se de certa indiferença ao objeto, uma sensação de satisfação diante do que é evidentemente visível, na qual se vê o que se vê e nada mais. Esta é a postura do homem da tautologia que, segundo o autor, terá feito tudo "para recusar as latências do objeto ao afirmar como um triunfo a identidade manifesta - minimal, tautológica - desse objeto mesmo: 'Esse objeto que vejo é aquilo que vejo, um ponto, nada mais"' (Ibid. p. 39). Essa atitude faz da experiência de ver um "exercício da tautologia": uma verdade rasa que resguarda uma verdade mais subterrânea e bem mais temível (Ibid.). Contentar-se com o que se vê na evidência da imagem é abrir mão de tudo o que pode acontecer.

Segundo o autor (Ibid.), não apenas a perspectiva da tautologia deve ser evitada, mas também a da crença. Se existe o homem da tautologia, existe também o seu oposto. Se no primeiro há cinismo, no segundo há fuga. $\mathrm{Na}$ crença, o que me olha já está dado; o túmulo, por exemplo, não representa o vazio, nem outra coisa além de fé e da certeza de que o enigma já foi resolvido, conforme aponta Didi-Huberman:

A "arte" cristã terá assim produzido as imagens inumeráveis de túmulos fantasmaticamente esvaziados de seus corpos - e portanto, num certo sentido, esvaziados de sua própria capacidade esvaziante ou angustiante. [...] é esse vazio de corpo que terá desencadeado para sempre toda a dialética da crença. (Ibid., p. 41, grifos do autor)

O homem da crença verá sempre algo além do que vê. Mas essa atitude é censurada pelo autor porque, ao esvaziar os túmulos de suas carnes putrefatas, o homem da crença os preenche de imagens que ele não criou. Estas imagens the foram dadas para confortar e informar ou, nas palavras do 
filósofo, para "fixar - nossas memórias, nossos temores e nossos desejos" (Ibid., p. 48, grifo do autor).

Nenhum dos dois ousa ver. O homem da tautologia não ousa ver porque não acredita que exista algo além da evidência do visível; o homem da crença não ousa ver porque se crê olhado pelo divino (Ibid.). Mas a imagem necessita de uma ousadia. Prefere-se, portanto, o entre; prefere-se a dialética.

Há uma clara opção pelas palavras olho, olhar e outras derivadas; contudo não é exclusivamente delas que se fala, ou não é necessariamente ao olhar físico que Didi-Huberman se refere. Há uma espécie de figura de linguagem que permite a compreensão do todo pela parte. O olho estaria, assim, sugerindo algo maior: o sentido.

Quando Didi-Huberman (Ibid.) contrapõe os extremos, com o homem da tautologia e o homem da crença, ele trata da relação com a imagem. Encarar a imagem como mera aparência - de modo que aquilo que vejo é aquilo que vejo e nada mais (tautologia) - é ignorar o que há de mais potente na imagem; é equivocadamente simplificar a questão e ater-se à superficialidade do que é visto. Por outro lado, encará-la como coisa autônoma (crença) é ignorar justamente a relação entre o que vemos e o que nos olha - o encontro, o entre. Delegar autonomia exclusiva à imagem é abrir mão de um direito que é nosso, um direito do olhante diante do olhado.

É necessário dialetizar a relação com o que vemos, pois o binarismo impede uma percepção complexa da imagem: não deveríamos escolher entre o que vemos (tautologia) e o que nos olha (crença), mas deveríamos inquietar-nos com o entre (Ibid.). Estar entre; ser o meio. Não é esse, justamente, o lugar da mediação?

Tanto no caso da tautologia como no caso da crença prescinde-se da dialética, tão cara a Didi-Huberman - e a Benjamin (1994) também. Em ambos os casos prefere-se tranquilizar o olhar, ao invés de inquietá-lo. Trata-se de um engodo no qual se ignora o tempo (de produção/recepção da obra e da própria experiência), o espaço (do espectador, do encontro) e o sujeito (e seu contexto), com a ilusão de que essas três instâncias poderiam ser estanques, fixadas ou prescindidas. E a mediação que pré-determina essas instâncias (tempo, espaço e sujeito) acaba se voltando contra a eficácia que ela própria reivindica. Mediações monologais são um 
exemplo claro disso: são falas previamente construídas que não dialogam com o espectador.

Se o lugar desejado para a experiência e para o sujeito da experiência, como foi dito até aqui, é um lugar de latência entre o que vemos e o que nos olha, um lugar de travessia, perigo e paixão, um território de passagem, um lugar de expor e se expor, esse também é o lugar desejado para a mediação e para o sujeito mediado.

A mediação busca o olhar para o túmulo de que Didi-Huberman (2010) nos fala. Não podemos nos limitar a ver apenas o volume geométrico. É preciso dar espaço à abertura que dentro de nós é latente e permitir que a coisa olhada nos olhe. É um trabalho de negação da tautologia, pois muitas coisas na nossa vida semeiam evidências tautológicas (da TV à escola). Assim, a mediação só faz sentido se for para inquietar o ver. É também um trabalho de descoberta e de invenção de sentidos. Mas sentidos são aqui compreendidos na amplitude proposta por John Dewey (2010, p. 88):

[o] "sentido" abarca uma vasta gama de conteúdos: o sensorial, o sensacional, o sensível, o sensato, o sentimental, junto com o sensual. [...] desde o choque físico e emocional cru até o sentido em si - ou seja, o significado das coisas presentes na experiência imediata.

Ora, é exatamente disso que trata a experiência estética, uma vez que tais conteúdos se revelam comprometidos com o regime estético, inclusive da arte.

Por fim, há uma expressão de Didi-Huberman (2010) que traz uma imagem interessante para pensarmos o lugar da mediação: "posições entrincheiradas". É nesse lugar que nos colocamos e, principalmente, colocamos o outro (espectador) quando assumimos uma mediação monologal. Quando, ao invés de instigar o olhar com questionamentos sensíveis, optamos por perguntas que exigem respostas "sim" ou "não". Quando preferimos informar a perguntar, ou a propor uma atividade que permita ao outro sentir e perceber no corpo o que se fala. Quando não praticamos a alteridade ou pretendemos a doutrinação. Quando, enfim, não nos colocamos no lugar próprio da mediação: na latência do entre, do meio; no limiar entre o que vejo e o que me olha. 


\section{Referências bibliográficas}

BENJAMIN, W. Magia e técnica, arte e política: ensaios sobre literatura e história da cultura. Tradução Sergio Paulo Rouanet. São Paulo: Brasiliense, 1994. (Obras escolhidas, v. 1).

BONDÍA, J. L. Notas sobre a experiência e o saber de experiência. Revista Brasileira de Educação, Rio de Janeiro, n. 19, p. 20-28, jan./abr. 2002.

DEWEY, J. Arte como experiência. Tradução Vera Ribeiro. São Paulo: Martins Fontes, 2010.

DIDI-HUBERMAN, G. O que vemos, o que nos olha. Tradução Paulo Neves. São Paulo: Editora 34, 2010.

LISPECTOR, Clarice. A paixão segundo G.H. 18. ed. Rio de Janeiro: Francisco Alves, 1995.

Recebido em 06/09/2017

Aprovado em 03/04/2018

Publicado em 29/06/2018 